\title{
Gastrointestinal lipolysis of lipid-based excipients intended for the oral drug delivery of poorly water-soluble drugs
}

\author{
Sylvie FERNANDEZ ${ }^{1,2}$ \\ Frédéric CARRIÈRE ${ }^{2}$ \\ Vincent JANNIN ${ }^{1}$ \\ ${ }^{1}$ Gattefossé SAS, 36, chemin de Genas, \\ 69804 Saint-Priest, France \\ <vjannin@gattefosse.com> \\ 2 Laboratoire d'enzymologie interfaciale \\ et de physiologie de la lipolyse, \\ CNRS UPR 9025, 31, chemin Joseph-Aiguier, \\ 13402 Marseille cedex 20, France
}

\begin{abstract}
Labraso ${ }^{\circledR}$ and Gelucire ${ }^{\circledR} 44 / 14$ are lipid-based excipients used for the oral drug delivery of poorly water-soluble drugs. These macrogolglycerides are composed of acylglycerols and PEG esters, potential substrates of digestive lipases. We developed an in vitro method to simulate the gastrointestinal lipolysis of these excipients and to evaluate the impact of lipolysis in vivo. At the end of the gastric phase, the composition of both excipients was significantly modified underlining the importance of gastric lipolysis in vivo. We also studied the influence of excipients' lipolysis on the solubilization of a poorly water-soluble drug, cinnarizine, in aqueous phase. Gastrointestinal lipolysis of Labraso ${ }^{\circledR}$ was a prerequisite to maintain cinnarizine in aqueous solution, whereas the lipolysis of Gelucire ${ }^{\circledR} 44 / 14$ did not affect the cinnarizine solubilization.
\end{abstract}

Key words: oral drug delivery, gastrointestinal lipolysis, poorly water-soluble drugs, macrogolglycerides, lipases, lipid-based formulations
Oral administration of drugs exhibiting poor solubility in gastrointestinal fluids is one of the main challenges of the pharmaceutical industry. To improve oral bioavailability of poorly water-soluble drugs, innovative formulations such as self-emulsifying drug delivery systems (SEDDS), and self-microemulsifying drug delivery systems (SMEDDS), are developed (Charman et al., 1997; Holm et al., 2003). SEDDS and SMEDDS are isotropic mixtures of oil, surfactant, cosurfactant, and drug that form, under gentle stirring, oil-in-water emulsions or microemulsions, respectively (Charman et al., 1992). Among the different self-emulsifying excipients available, Labrasol $^{\circledR}$ and Gelucire ${ }^{\circledR} 44 / 14$ are macrogolglycerides able to form microemulsions in contact with gastrointestinal fluids. Labrasol $^{\circledR}$ and Gelucire $^{\circledR} 44 / 14$ are obtained by polyglycolysis of medium-chain triacylglycerols or mediumand long-chain triacylglycerols and PEG-8 or PEG-32, respectively. These excipients are a mixture of mono-, di-, and triacylglycerols and mono- and diesters of PEG, and free PEG. Labrasol $^{\circledR}$ and Gelucire ${ }^{\circledR} 44 / 14$ significantly increase the bioavailability of various poorly water-soluble drugs (Hauss et al., 1998; Hu et al., 2001; Eaimtrakarn et al., 2002; Barker et al., 2003; Rama Prasad et al., 2003; Rama Prasad et al., 2004), but the mechanisms underlining these effects still remain to be elucidated.

In humans, the digestion of dietary triacylglycerols starts in the stomach with the gastric lipase (Carriere et al., 1993). The free fatty acids
(FFAs) released in the stomach are essential to stimulate biliary and pancreatic secretions, as well as for the subsequent action of pancreatic lipase (Gargouri et al., 1986; Bernback et al., 1989). Thanks to the gastric emptying, the lipolysis continues in the duodenum where the chyme is mixed with bile and pancreatic juice which contains several lipolytic enzymes able to hydrolyze various natural substrates such as triacylglycerols, phospholipids, galactolipids, and vitamin esters (De Caro et al., 2004; Eydoux et al., 2007). We have already shown that in vitro, Labrasol ${ }^{\circledR}$ and Gelucire ${ }^{\circledR}$ $44 / 14$ were hydrolyzed by several digestive lipases (Fernandez et al., 2007; Fernandez et al., 2008). These findings suppose that in vivo, these excipients are hydrolyzed by digestive lipases and their lipolytic products might play an important role in the transport of the drug from the formulation to the mixed micelles and/or the unstirred water layer next to the enterocytes.

To mimic the gastrointestinal lipolysis, we developed an in vitro method that considers both gastric and duodenal steps of digestion, the first step being not taken into consideration in most of the studies on bioavailability and/or solubility of poorly water-soluble drugs (Sek et al., 2001; Sek et al., 2002). Using this model, we studied the changes in the composition of both Labrasol ${ }^{\circledR}$ and Gelucire ${ }^{\circledR} 44 / 14$ during their in vitro lipolysis. The aim of this study was to perform similar experiments in presence of a poorly water-soluble drug, cinnarizine, a piperazine derivative with antihistaminic activ- ity and mainly used for the control of vomiting due to motion sickness, and to follow the concentration of cinnarizine dissolved in the aqueous phase during the lipolysis of Labrasol $^{\circledR}$ or Gelucire ${ }^{\circledR} 44 / 14$.

\section{Experimental procedure}

Labrasol ${ }^{\circledR}$ and Gelucire ${ }^{\circledR} 44 / 14$ are lipid-based excipients composed of acylglycerols (mono-, di-, and triacylglycerols, $10 \%$ and $20 \% \mathrm{w} / \mathrm{w}$, respectively) and of PEG esters (mono- and diesters) and free PEG corresponding to $90 \% \mathrm{w} / \mathrm{w}$ and $80 \% \mathrm{w} / \mathrm{w}$ of Labrasol ${ }^{\circledR}$ and Gelucire $^{\circledR} 44 / 14$, respectively.

Experimental conditions were based on in vivo data recorded at $50 \%$ gastric emptying of test meals, both in the stomach and in the duodenum. Enzyme solutions were prepared based on the lipase levels recorded in vivo during a meal (Carriere et al., 2000). The gastric enzyme solution was prepared using recombinant dog gastric lipase (rDGL) and the pancreatic enzyme solution was prepared using porcine pancreatic extracts (PPE).

Experiments were performed during 90 min to simulate gastrointestinal digestion of lipids (Fernandez et al., 2009). An emulsion of either Labrasol $^{\circledR}$ or Gelucire ${ }^{\circledR} 44 / 14$ in the assay solution was mechanically stirred in a temperaturecontrolled reaction vessel at $37^{\circ} \mathrm{C}$. At $\mathrm{t}=0 \mathrm{~min}$, the gastric lipase solution was added to the reaction vessel and, using a $\mathrm{pH}$-stat device, the $\mathrm{pH}$ was kept constant at 5.5 for $30 \mathrm{~min}$ (gastric step of lipolysis), via an automated 
titration of FFAs with $0.1 \mathrm{M} \mathrm{NaOH}$. At $\mathrm{t}=30 \mathrm{~min}$, pancreatic enzyme solution was added to the mixture and the $\mathrm{pH}$ was shifted to 6.25 and kept constant for $60 \mathrm{~min}$. At several time points, samples were taken and treated to be analyzed. Acylglycerols were assayed by GPC-FID method, whereas the quantification of PEG derivatives (PEG esters and free PEG) was done by HPLC (Fernandez et al., 2009).

The same experiments as described above were performed using $25 \mathrm{mg}$ cinnarizine formulated in $1.5 \mathrm{~g}$ of either Labrasol ${ }^{\circledR}$ or Gelucire $^{\circledR} 44 / 14$. The amount of cinnarizine dissolved in aqueous solution was determined by HPLC. A control experiment was also performed without enzymes to determine the influence of experimental conditions such as dilution and $\mathrm{pH}$ on cinnarizine solubilization.

\section{In vitro gastrointestinal lipolysis of Labrasol ${ }^{\circledR}$ and Gelucire ${ }^{\circledR}$ 44/14}

To identify which compounds and/or lipolysis products of Labrasol $^{\circledR}$ and Gelucire ${ }^{\circledR} 44 / 14$ were responsible for maintaining poorly water-soluble drugs in aqueous solution, we studied the changes in the composition of both excipients during their gastrointestinal lipolysis. The experiments, performed here, were based on in vivo data recorded during test meal digestion. The gastric lipolysis step was simulated using rDGL which is known to be a good model of human gastric lipase (Bodmer et al., 1987; Carriere et al., 1991; Vaganay et al., 1998), at pH 5.5, the mean pH value found in the stomach at $50 \%$ of gastric emptying. A solution of PPE was then added to the reaction mixture in order to perform the duodenal step of lipolysis. PPE were used as a model of human pancreatic juice. Indeed, we previously showed that human pancreatic juice and porcine pancreatic extracts presented similar lipolytic activities on both Labrasol ${ }^{\circledR}$ and Gelucire $^{\circledR}$ 44/14 (Fernandez et al., 2007; Fernandez et al., 2008), although their enzyme compositions are slightly different. Moreover, the volume of pancreatic enzyme solution added was adapted to obtain a 1.7-fold dilution of the gastric phase which corresponds to the dilution of the chyme by biliary and pancreatic secretions that occurs in vivo (Carriere et al., 2000). It is important to mention that dilution can also affect drug solubility. The $\mathrm{pH}$ value was increased to 6.25 during the duodenal step of lipolysis which corresponds to the mean $\mathrm{pH}$ value found in the duodenum during digestion of a test meal at $50 \%$ of gastric emptying.

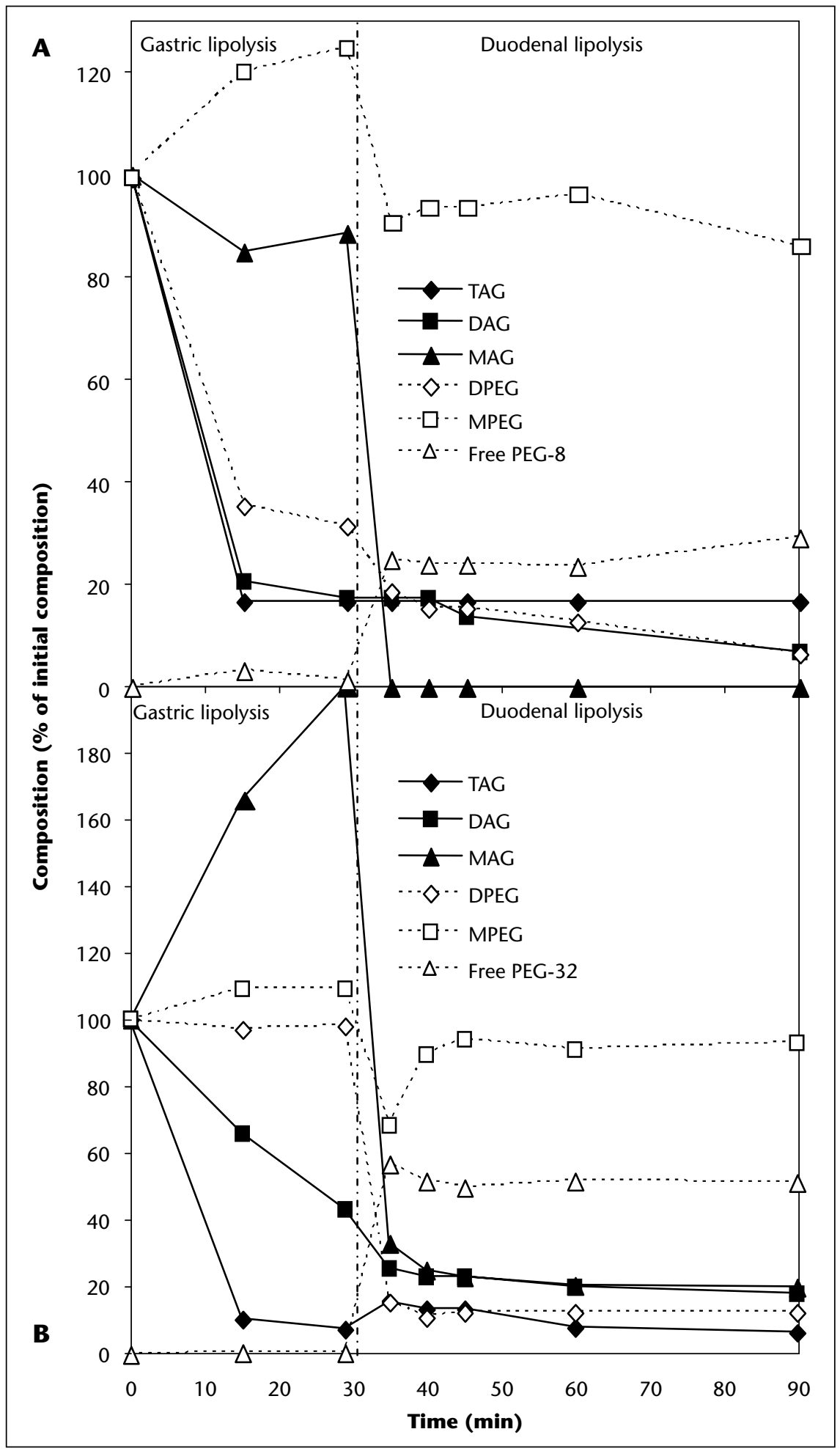

Figure 1. Evolution of the composition of Labraso ${ }^{\circledR}(A)$ and Celucire ${ }^{\circledR} 44 / 14$ (B) during their gastrointestinal lipolysis by $r D G L$ and PPE as a function of time. The vertical line at 30 min represents the end of gastric lipolysis step and the beginning of duodenal lipolysis step. The variations are expressed in percent of mono-, di-, and triacylglycerols (MAG, DAG, and TAG, respectively) and PEG mono- and diesters (MPEG and DPEG, respectively) initially present in the excipients. For free PEG, only the amount of free PEG released upon the lipolysis of PEG esters are shown and expressed in percent of the amounts of PEG initially present in the excipients. Adapted from Fernandez et al., 2009. 
Figure 1 presents the variations in the composition of Labrasol ${ }^{\circledR}$ and Gelucire ${ }^{\circledR} 44 / 14$ during their in vitro gastrointestinal lipolysis. For each family of compounds, the results are expressed in percent of the initial composition and as a function of time. Concerning free PEG, the results shown here correspond to the free PEG released, expressed in percent of the amounts of free PEG initially present in excipients.

During the gastric lipolysis step of Labrasol ${ }^{\circledR}$, C8-C10 di- and triacylglycerols and PEG-8 diesters were rapidly hydrolyzed, whereas $\mathrm{C} 8-\mathrm{C} 10$ monoacylglycerols and PEG-8 monoesters were poor substrates of gastric lipase (figure 1A). Consequently, at the end of gastric lipolysis phase, C8-C10 monoacylglycerols and PEG-8 monoesters were the main hydrolyzable compounds of Labrasol $^{\circledR}$ remaining before duodenal lipolysis.

The addition of pancreatic enzymes led to major changes. Indeed, C8-C10 monoacylglycerols were rapidly and totally hydrolyzed within $5 \mathrm{~min}$ after the addition of pancreatic enzymes contrary to the residual C8-C10 di- and triacylglycerols and PEG-8 diesters, which were slightly hydrolyzed during the duodenal step of lipolysis. PEG-8 monoesters were also hydrolyzed as shown by the increase in free PEG-8. At the end of the gastrointestinal simulation, the main compounds of Labrasol ${ }^{\circledR}$ remaining were PEG-8 monoesters and free PEG-8 (Fernandez et al., 2009).

During the gastric lipolysis step of Gelucire $^{\circledR} 44 / 14$, results were quite different from those found with Labrasol ${ }^{\circledR}$ (figure 1B). During the gastric phase of lipolysis, C8-C18 di- and triacylglycerols were rapidly hydrolyzed and an accumulation of C8-C18 monoacylglycerols was observed. PEG-32 mono- and diesters were not hydrolyzed. Consequently, at the end of gastric lipolysis phase, C8-C18 monoacylglycerols and PEG-32 mono- and diesters were the main hydrolysable compounds of Gelucire ${ }^{\circledR} 44 / 14$ remaining before duodenal lipolysis.

After addition of pancreatic lipases, C8-C18 monoacylglycerols and PEG-32 mono- and diesters rapidly decreased and free PEG-32 was rapidly released. Residual C8-C18 diacylglycerols were also hydrolyzed. At the end of the gastrointestinal simulation, the main compounds of Gelucire ${ }^{\circledR} 44 / 14$ remaining were PEG-32 monoesters and free PEG-32 (Fernandez et al., 2009).

Labrasol $^{\circledR}$ and Gelucire ${ }^{\circledR} 44 / 14$ correspond to a mixture of acylglycerols, responsible for the solubilization of lipophilic drugs (Pouton and Porter, 2008), PEG esters, amphiphilic molecules responsible for the surfactant properties, and free PEG which plays a role of cosolvent. In vivo, the hydrolysis of acylglycerols and PEG esters contained in both excipients might have a major influence on the fate of a poorly watersoluble drug in the gut. The results found here suggest that in vivo, monoacylglycerols and PEG esters, and particularly PEG monoesters, will have a major role to maintain poorly water-soluble drugs in aqueous solution during the gastric digestion.

Concerning the duodenal lipolysis phase, the results suggest that PEG monoesters probably play a crucial role in vivo to maintain the drug in solution in the small intestine. Concerning free PEG, it seems difficult that this cosolvent has a major role in the fate of the drug during the in vivo lipolysis. Indeed, water-soluble cosolvents such as PEG-8 are used to increase the solvent capacity of the formulation, but they loose rapidly their solvent capacity after dispersion of the formulation in an aqueous phase (Pouton and Porter, 2008).

\section{Solubilization \\ of cinnarizine during in vitro gastrointestinal lipolysis of Labrasol ${ }^{\circledR}$ and Gelucire ${ }^{\circledR}$ 44/14}

We studied the concentration of cinnarizine dissolved in the aqueous phase, during in vitro gastrointestinal lipolysis of either Labrasol ${ }^{\circledR}$ or Gelucire $^{\circledR} 44 / 14$. For each formulation, a blank experiment was performed without any enzyme, to evaluate the precipitation of cinnarizine due to experimental parameters such as assay solution, dilution, and $\mathrm{pH}$ variation. Figure 2 shows the variation with time of cinnarizine dissolved in the aqueous phase during in vitro gastrointestinal lipolysis of the two excipients. In both cases, lipid excipients led to a complete solubilization of cinnarizine in the gastric milieu after dispersion $(t=0 \mathrm{~min})$. When cinnarizine was formulated with Labrasol $^{\circledR}$, the results obtained during the Labrasol $^{\circledR}$ lipolysis were significantly different from those obtained without enzymes (figure 2A). In the absence of enzymes and therefore lipolysis, the dilution of the formulation induced a dramatic precipitation of the drug which increased with time until the end of the experiment. Under these conditions, the percentage of cinnarizine remaining in solution was 63-times higher than its solubility in the assay solution at $\mathrm{pH} 6.25$. Hence, Labrasol $^{\circledR}$ helps keeping the drug in supersaturation (63-fold) even after dilution and change of $\mathrm{pH}$. When Labrasol ${ }^{\circledR}$ was hydrolyzed by digestive lipases, the overall cinnarizine precipitation was however much lower and the concentra- tion of cinnarizine dissolved in the aqueous phase was equivalent to a 142-fold supersaturation. It is worth noticing that, in this case, cinnarizine precipitation was initiated during the gastric lipolysis step but was not significantly affected by the dilution of the gastric medium by the pancreatic enzyme solution.

During the gastrointestinal lipolysis of Labrasol $^{\circledR}$, PEG-8 monoesters were the only compounds which remained at a high level (figure 1A). One can therefore assume that PEG-8 monoesters, the main surface active components initially present in Labrasol ${ }^{\circledR}$, were involved in maintaining the drug dissolved during gastrointestinal lipolysis of this excipient.

When cinnarizine was formulated with Gelucire $^{\circledR} 44 / 14$, no differences were observed in absence or in presence of enzymes (figure 2B). Cinnarizine precipitation only occurred when the gastric medium was diluted whatever the fate of Gelucire ${ }^{\circledR} 44 / 14$ (hydrolyzed or not).

Since the percentage of PEG-32 monoesters remained high during the gastrointestinal lipolysis (figure 1B), PEG-32 monoesters might play a key role to maintain cinnarizine in aqueous solution, as in the case of Labrasol $^{\circledR}$. Cinnarizine precipitation due to the dilution of the gastric medium might be attributable to a greater solubilization of PEG-32 monoesters.

Whatever the experimental conditions, when cinnarizine was formulated with Gelucire $^{\circledR} 44 / 14$, the solubility of cinnarizine was increased as compared to solubility of cinnarizine in the assay solution, leading to a 144fold and 133-fold supersaturation of cinnarizine with and without enzymes, respectively.

\section{Conclusion}

We studied in parallel the evolution of the composition of lipid-based excipients during their in vitro gastrointestinal lipolysis and the resulting precipitation of a poorly water-soluble drug. We showed that gastrointestinal lipolysis of both Labrasol ${ }^{\circledR}$ and Gelucire ${ }^{\circledR} 44 / 14$ had a significant impact on the composition of both excipients. Our results highlight the importance of gastric digestion step which was not taken into account in the in vitro bioavailability studies performed so far.

The cinnarizine precipitation strongly depended on the excipient used. When cinnarizine was formulated with Labrasol $^{\circledR}$, the lipolysis of Labrasol $^{\circledR}$ significantly affected the fate of cinnarizine. Precipitation of cinnarizine due to the dilution of the gastric medium did not 


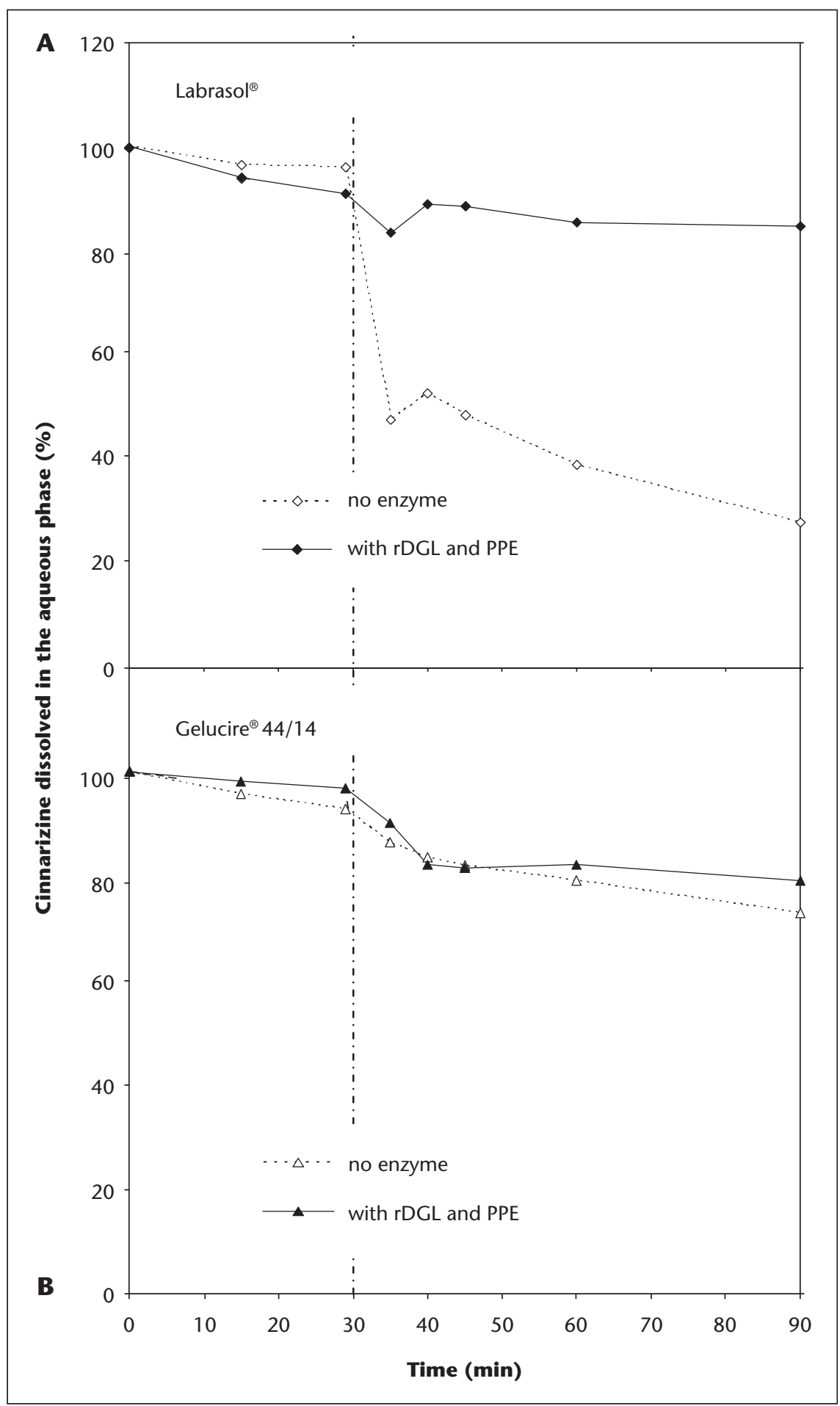

Figure 2. Evolution of the concentration of cinnarizine dissolved in the aqueous phase, expressed in percent of the initial dose, during the gastrointestinal lipolysis by rDGL and PPE of Labraso ${ }^{\circledR}(A)$ and Celucire ${ }^{\circledR} 44 / 14$ (B) as a function of time. The vertical line at $30 \mathrm{~min}$ represents the end of gastric lipolysis step and the beginning of duodenal lipolysis step. Adapted from (Fernandez et al., 2009).

\section{Thèse soutenue le 31 octobre 2008 à Marseille devant le jury suivant :}

Pr Frédéric Fotiadu : École centrale Marseille (examinateur)

Dr Frédéric Carrière : CNRS (examinateur) DrVincent Jannin (examinateur): Gattefossé $\operatorname{Pr}$ Anette Müllertz (rapporteur) : University of Copenhagen, Denmark

$\operatorname{Pr}$ Thierry Vandamme (rapporteur): Université Louis Pasteur

occur when Labrasol ${ }^{\circledR}$ was hydrolyzed. This finding supposes that in vivo Labrasol ${ }^{\circledR}$ lipolysis is a prerequisite to prevent cinnarizine form precipitation and keep the drug in supersaturation in the gastrointestinal milieu. No effect of the lipolysis was observed on cinnarizine precipitation when using Gelucire ${ }^{\circledR} 44 / 14$ as lipid-based vehicle.

Acknowledgments. Sylvie Fernandez's PhD research was supported by a CIFRE contract from Association Nationale de la Recherche Technique (ANRT, France).

\section{REFERENCES}

Barker SA, Yap SP, Yuen KH, et al. An investigation into the structure and bioavailability of alphatocopherol dispersions in Gelucire 44/14. J Control Release 2003; 91: 477-88.

Bernback S, Blackberg L, Hernell O. Fatty acids generated by gastric lipase promote human milk triacylglycerol digestion by pancreatic colipase-dependent lipase. Biochim Biophys Acta 1989; 1001: 286-93.

Bodmer MW, Angal S, Yarranton GT, et al. Molecular cloning of a human gastric lipase and expression of the enzyme in yeast. Biochim Biophys Acta 1987; 909: 237-44.

Carriere F, Barrowman JA, Verger R, et al. Secretion and contribution to lipolysis of gastric and pancreatic lipases during a test meal in humans. Gastroenterology 1993; 105: 876-88.

Carriere F, Moreau H, Gargouri Y, et al. Purification and biochemical characterization of dog gastric lipase. Eur J Biochem 1991; 202: 75-83.

Carriere F, Renou C, Lopez V, et al. The specific activities of human digestive lipases measured from the in vivo and in vitro lipolysis of test meals. Gastroenterology 2000; 119: 949-60. 
Charman SA, Charman WN, Rogge MC, et al. Selfemulsifying drug delivery systems: formulation and biopharmaceutic evaluation of an investigational lipophilic compound. Pharm Res 1992; 9: 87-93.

Charman WN, Porter Cl, Mithani S, et al. Physiochemical and physiological mechanisms for the effects of food on drug absorption: the role of lipids and pH. J Pharm Sci 1997; 86: 269-82.

De Caro J, Sias B, Grandval P, et al. Characterization of pancreatic lipase-related protein 2 isolated from human pancreatic juice. Biochim Biophys Acta 2004; 1701: 89-99.

Eaimtrakarn S, Rama Prasad YV, Ohno T, et al. Absorption enhancing effect of labrasol on the intestinal absorption of insulin in rats. / Drug Target 2002; 10: 255-60.

Eydoux C, De Caro J, Ferrato F, et al. Further biochemical characterization of human pancreatic lipase-related protein 2 expressed in yeast cells. J Lipid Res 2007; 48: 1539-49.

Fernandez S, Chevrier S, Ritter N, et al. In vitro gastrointestinal lipolysis of four formulations of piroxicam and cinnarizine with the self emulsifying excipients Labrasol and Gelucire 44/14. Pharm Res 2009; 26: 1901-10.
Fernandez S, Jannin V, Rodier JD, et al. Comparative study on digestive lipase activities on the self emulsifying excipient Labrasol, medium chain glycerides and PEG esters. Biochim Biophys Acta 2007; 1771: 633-40.

Fernandez S, Rodier JD, Ritter N, et al. Lipolysis of the semi-solid self-emulsifying excipient Gelucire 44/14 by digestive lipases. Biochim Biophys Acta 2008; 1781: 367-75.

Gargouri Y, Pieroni G, Rivière C, et al. Importance of human gastric lipase for intestinal lipolysis: an in vitro study. Biochim Biophys Acta 1986; 879: 419-23.

Hauss DJ, Fogal SE, Ficorilli JV, et al. Lipid-based delivery systems for improving the bioavailability and lymphatic transport of a poorly water-soluble LTB4 inhibitor. J Pharm Sci 1998; 87: 164-9.

Holm R, Porter C], Edwards GA, et al. Examination of oral absorption and lymphatic transport of halofantrine in a triple-cannulated canine model after administration in self-microemulsifying drug delivery systems (SMEDDS) containing structured triglycerides. Eur J Pharm Sci 2003; 20: 91-7.

Hu Z, Tawa R, Konishi T, et al. A novel emulsifier, labrasol, enhances gastrointestinal absorption of gentamicin. Life Sci 2001; 69: 2899-910.
Pouton CW, Porter C]. Formulation of lipid-based delivery systems for oral administration: materials, methods and strategies. Adv Drug Deliv Rev 2008; 60: 625-37.

Rama Prasad YV, Eaimtrakarn S, Ishida M, et al. Evaluation of oral formulations of gentamicin containing labrasol in beagle dogs. Int / Pharm 2003; 268: 13-21.

Rama Prasad YV, Minamimoto T, Yoshikawa Y, et al. In situ intestinal absorption studies on low molecular weight heparin in rats using labrasol as absorption enhancer. Int J Pharm 2004; 271: 225-32.

Sek L, Porter C), Charman WN. Characterisation and quantification of medium chain and long chain triglycerides and their in vitro digestion products, by HPTLC coupled with in situ densitometric analysis. J Pharm Biomed Anal 2001; 25: 651-61.

Sek L, Porter Cl, Kaukonen AM. Evaluation of the in-vitro digestion profiles of long and medium chain glycerides and the phase behaviour of their lipolytic products. J Pharm Pharmacol 2002; 54: 29-41.

Vaganay S, Joliff G, Bertaux O, et al. The complete CDNA sequence encoding dog gastric lipase. DNA Seq 1998; 8: 257-62. 